\title{
Information to Help Families Meet Their Breastfeeding Goals
}

Christian I.J. Minter

University of Nebraska Medical Center, christian.minter@unmc.edu

Tell us how you used this information in this short survey.

Follow this and additional works at: https://digitalcommons.unmc.edu/mcgoogan_articles

Part of the Library and Information Science Commons

\section{Recommended Citation}

Minter, Christian I.J., "Information to Help Families Meet Their Breastfeeding Goals" (2019). Journal Articles: Leon S. McGoogan Health Sciences Library. 7.

https://digitalcommons.unmc.edu/mcgoogan_articles/7

This Article is brought to you for free and open access by the Leon S. McGoogan Health Sciences Library at DigitalCommons@UNMC. It has been accepted for inclusion in Journal Articles: Leon S. McGoogan Health Sciences Library by an authorized administrator of DigitalCommons@UNMC. For more information, please contact digitalcommons@unmc.edu. 
This is an Accepted Manuscript of an article published by Taylor \& Francis in the Journal of Consumer Health on the Internet on 04/16/19, available online: https://www.tandfonline.com/doi/full/10.1080/15398285.2019.1573073.

\title{
WEBHEALTH TOPICS
}

\section{Priscilla L. Stephenson and Mary Virginia Taylor, Column Editors}

\section{Information to Help Families Meet Their Breastfeeding Goals Christian I.J. Minter}

\begin{abstract}
Breast milk is the recommended food source for infants during their first year of life. Although the rates for parents that initiate breastfeeding their baby are increasing, rates for those who continue breastfeeding past six months are much lower. Parents face a great deal of misinformation and misconceptions about the benefits of breastfeeding, how breastfeeding works, how to address challenges, and who to turn to for help. It is important for families to have all the facts, especially facts backed by science, to make the decision on whether to breastfeed, and, for those who do breastfeed, to successfully meet their breastfeeding goals. The online resources shared in this article will provide parents with evidence-based information on breastfeeding and related issues and resources to support the role of employers, childcare care providers, health professionals, and other community members in contributing to breastfeeding success.
\end{abstract}

KEYWORDS: Breastfeeding, lactation, nursing 
AUTHOR: Christian I.J. Minter, MSLIS (christian.minter@unmc.edu) is Community Engagement and Health Literacy Librarian, McGoogan Library of Medicine, University of Nebraska Medical Center, 986705 Nebraska Medical Center, Omaha, NE 68198-6705.

Comments and suggestions should be sent to the Column Editors: Priscilla L. Stephenson (Priscilla.Stephenson@va.gov) and Mary Virginia Taylor (mvtaylor48@bellsouth.net). 


\section{INTRODUCTION}

Breast milk is the ideal first food to meet the nutritional and developmental needs of babies during their first year of life. Easy to digest and absorb, breast milk contains a unique recipe of ingredients that can only be partially replicated at present. These ingredients include macronutrients such as fats, carbohydrates, and proteins; micronutrients such as calcium, iron, and vitamins; and living cells such as leukocytes, probiotic bacteria, and stem cells. This dynamic liquid can adjust its composition during a feeding and over the course of lactation to respond to a baby's changing needs related to age, health, and development (Kim \& Froh 2012; Witkowska-Zimny \& Kaminska-El-Hassan 2017).

Breast milk provides health benefits and protective properties for both babies and mothers. Babies who are breastfed have a reduced risk of ear infection, childhood obesity, asthma, sudden infant death syndrome (SIDS), type 2 diabetes, pneumonia, and childhood leukemia and lymphoma. Although any amount of breastfeeding is beneficial, babies who are exclusively breastfed for the first six months of life receive more health benefits. For mothers, breastfeeding helps the uterus contract to normal size more quickly and reduces post-delivery blood loss. Mothers who breastfeed one year or longer benefit from a reduced risk of breast cancer, heart disease, rheumatoid arthritis, and type 2 diabetes (American Academy of Pediatrics 2012; Office of the Surgeon General 2011).

The American Academy of Pediatrics and the Academy of Nutrition and Dietetics recommend exclusive breastfeeding — breastmilk without any other food or drink—for the first six months and continued breastfeeding along with solid food until one year of age or longer (AAP 2012; Lessen \& Kavanaugh 2015). The World Health Organization also recommends 
exclusive breastfeeding for six months and encourages continued breastfeeding for two years or longer (World Health Organization 2003).

One of the aims of Healthy People 2020 is to increase the rates for the initiation and continuation of breastfeeding in the United States (Office of Disease Prevention and Health Promotion 2010). The rate of breastfeeding initiation has been rising nationally (over $80 \%$ ), however, rates for continued breastfeeding at six and twelve months are much lower (Centers for Disease Control and Prevention 2018). Many parents are interested in breastfeeding, but they face barriers that prevent them from continuing the recommended length of time. There are also breastfeeding disparities based on zip code and race/ethnicity. For example, there are lower rates of breastfeeding in the southeastern states and among African American and Native American families (Antsey et al. 2017; Jones et al. 2015).

There are multiple reasons why parents may stop breastfeeding sooner than planned. Some may face issues with insufficient milk supply or certain medical conditions that affect breastfeeding. However, for many parents it often boils down to misinformation, lack of professional breastfeeding support, or work policies that are not conducive to long-term breastfeeding. Studies have shown that not receiving enough prenatal education on breastfeeding, receiving negative messages on breastfeeding from family and friends, and not having a breastfeeding friendly hospital or doctor can contribute to early cessation of breastfeeding. Many parents have concerns about breastfeeding, including maintaining a milk supply, pain, infant weight loss/gain, the mother's health, and other breastfeeding related processes such as pumping (Sriraman \& Kellams 2016; Odom et al. 2013). Without adequate knowledge to overcome these challenges or concerns, it becomes easier to stop breastfeeding altogether. 
The decision to breastfeed is personal, and parents need access to evidence-based information to make the best choice for their family. The organizations that recommend breastfeeding also acknowledge the need for health professionals and community groups to provide adequate support to help families meet their breastfeeding goals. Even though breastmilk is a natural food source, the act of breastfeeding is a learned skill. Parents often need education to learn how to breastfeed, overcome challenges, and fit breastfeeding into their daily life. Access to quality information and support from family and friends, employers, and health care providers is essential to breastfeeding success.

\section{GENERAL RESOURCES ON BREASTFEEDING}

\section{KellyMom}

\section{$<\underline{\text { https://kellymom.com/> }}$}

KellyMom provides evidence-based and easy-to-read information on breastfeeding and parenting. Kelly Bonyata, an International Board Certified Lactation Consultant (IBCLC), manages the site and writes most of the articles. This is a comprehensive resource which offers articles on almost every aspect of breastfeeding. Families can find information on preparing for breastfeeding, how breasts produce milk, establishing and maintaining milk supply, pumping and returning to work, breastfeeding at the different stages of development from newborn to toddler, introducing solid foods, and many other topics. There are also articles on breast or chestfeeding for transgender parents and induced lactation for adoptive parents. Most of Kelly's articles include links to other trustworthy sites for additional information as well as a list of references. 
Some advertisements are included on the site, and KellyMom selects monthly sponsors based on their alignment with the values of the website and compliance with the World Health Organization's International Code of Marketing Breast-Milk substitutes. Previous sponsors have included companies selling products for breastfeeding or pumping, dietary supplements, and books.

\section{MedlinePlus: Breastfeeding}

\section{$<$ https://medlineplus.gov/breastfeeding.html $>$}

The U.S. National Library of Medicine created MedlinePlus for patients and families. There are over 1,000 health and wellness topics covered in addition to information on prescription drugs, dietary supplements, and lab tests. The site also includes a medical encyclopedia, videos, and other interactive tools to help users learn about their health. Available in both English and Spanish, MedlinePlus also offers resources on selected topics in over forty other languages. Free from advertisements, each topic page is written in simple language and includes a list of links for carefully selected webpages and publications from federal agencies and other reputable organizations.

The breastfeeding page provides a brief explanation of the benefits of breastfeeding, and a list of links to information on getting started with breastfeeding and other related issues. Families can also find images of nursing positions, journal articles, clinical trials, and downloadable handouts. This page links to handouts in fourteen languages on breastfeeding basics, common breastfeeding challenges, and pumping and storing breast milk. Users can sign up to receive email updates when new information is added to the page. 


\section{WomensHealth.gov: Breastfeeding}

$<$ https://www.womenshealth.gov/breastfeeding/>

The Office on Women's Health in the U.S. Department of Health and Human Services manages WomensHealth.gov. This website provides information for women on general health and wellness, reproductive health, and specific diseases and their effects on women. Topics are written in simple terms and the website is easy to navigate. Each topic page includes links for additional information and a list of references used to write the article. Any content created by WomensHealth.gov is in the public domain and may be reused or reproduced without permission.

Breastfeeding is one of the most popular topics on this site. Families can find information to support them in making the decision to breastfeed, learning how to breastfeed, overcoming breastfeeding challenges, pumping and storing breast milk, and breastfeeding after returning to work (Figure 1). In addition to the online articles, there is a fact sheet on breastfeeding, a series of videos on different breastfeeding topics, and a 60-page booklet, Your Guide to Breastfeeding, available for download that addresses common questions and concerns of new breastfeeding parents.

\section{[PLACE FIGURE 1 HERE]}

\section{Text for FIGURE 1: Figure 1. WomensHealth.gov website}

\section{WomensHealth.gov: It's Only Natural}

$<$ https://www.womenshealth.gov/its-only-natural/>

In 2013, The Office on Women's Health launched a campaign to help reduce breastfeeding disparities by helping African American families learn about the health benefits of 
breastfeeding. The It's Only Natural section of WomensHealth.gov provides information on planning ahead for breastfeeding, common breastfeeding myths, overcoming breastfeeding challenges, finding community support, and fitting breastfeeding into daily life. Other resources include an infographic on the growing number of mothers breastfeeding and a series of videos that feature mothers sharing their experience with breastfeeding.

\section{RESOURCES ON BREASTFEEDING AND MEDICATION}

\section{Infant Risk Center}

$<\underline{\text { https://wWw.infantrisk.com> }}$

The InfantRisk Center is located at the Texas Tech University Health Sciences Center and provides evidence-based information on the use of medication during pregnancy and breastfeeding. Dr. Thomas Hale is the executive director and is a leading expert on perinatal pharmacology. The Center's goal is to educate families and health professionals and help reduce the number of dangerous exposures and birth defects related to medications. The website provides research articles and updates related to drugs and chemicals and their safety for pregnancy and breastfeeding. Parents can ask questions through online forums or a national call center. Retired registered nurses are available to answer the questions in consultation with Dr. Hale. The InfantRisk Center also offers the MommyMeds app for parents to access information on the safety of prescription and over-the-counter drugs. The app is available for $\$ 3.99$ for iOS and Android devices.

\section{LactMed $^{\circledR}$}

$<\underline{\text { https://toxnet.nlm.nih.gov/newtoxnet/lactmed.htm }>~}$ 
The U.S. National Library of Medicine developed the LactMed database to provide evidence-based information on the safety of drugs and chemicals that mothers may be exposed to while breastfeeding. Health professionals and parents can use this resource to determine the levels of drugs and chemicals found in breast milk and infant blood after exposure and to find available research on the effect on lactation or the nursing infant. Alternatives drugs are recommended when appropriate. The database allows searching by the drug's generic and brand name. A free LactMed app is available for both iOS and Android devices (Figure 2). All information is supported by scientific literature and the database is updated monthly.

\section{[PLACE FIGURE 2 HERE]}

\section{Text for FIGURE 2: Figure 2. LactMed Mobile App}

\section{RESOURCES ON BREASTFEEDING AND SAFE SLEEP}

\section{American Academy of Pediatrics: Safe Sleep \\ <https://www.aap.org/en-us/advocacy-and-policy/aap-health-initiatives/healthy-child- care/Pages/Safe-Sleep.aspx $>$}

Breastfeeding and safe sleep continues to be a controversial issue with conflicting views related to the pros and cons of co-sleeping and bed-sharing. When parents co-sleep, they are sleeping close to the baby, either in the same room or in the same bed. Parents who are bedsharing are sleeping in the same bed with the baby. There is research to support both sides of the issue, and it is up to each family to decide which sleeping arrangement works best in their situation to successfully meet breastfeeding goals. 
The American Academy of Pediatrics (AAP) does recommend co-sleeping for up to a year with parents and baby sleeping in the same room but on different surfaces. This webpage links to the AAP's safe sleep resources including the policy statement, SIDS and Other SleepRelated Infant Deaths: Updated 2016 Recommendations for Safe Infant Sleeping Environment and a technical report detailing the research used to support these recommendations. An article written for parents, How to Keep Your Sleeping Baby Safe: AAP Policy Explained, provides a simple explanation of the updated recommendations.

\title{
Safe Cosleeping Guidelines
}

$<$ https://cosleeping.nd.edu/safe-co-sleeping-guidelines/>

Dr. James J. McKenna is considered a leading expert in researching mother-baby cosleeping as it relates to breastfeeding and SIDS. He is the Director of the Mother-Baby Behavioral Sleep Laboratory at the University of Notre Dame. This webpage provides cosleeping guidelines developed by Dr. McKenna. The guidelines explain the characteristics of a safe sleeping environment and highlight the issues parents need to consider when deciding where a baby will sleep. For parents who choose to bed-share, these guidelines explain how to do so safely and identify situations where bed-sharing would not be appropriate.

\section{RESOURCES ON BREASTFEEDING LAWS}

\author{
National Conference of State Legislatures: Breastfeeding State Laws
}

$<\underline{\text { http://www.ncsl.org/research/health/breastfeeding-state-laws.aspx }>}$ 
This webpage provides information on federal and state breastfeeding laws. All fifty states, the District of Columbia, Puerto Rico, and the Virgin Islands have passed laws to protect the rights of mothers to breastfeed in any public or private place. States may also have laws related to other aspects of breastfeeding such as jury duty, hospital initiatives, and workplace and childcare policies. This list of laws can be searched by keyword or sorted by state.

\section{United States Breastfeeding Committee: Federal Workplace Law <http://www.usbreastfeeding.org/workplace-law>}

The United States Breastfeeding Committee (USBC) is a nonprofit organization that protects, promotes, and supports breastfeeding. The USBC created this webpage to provide information on the federal "Break Time for Nursing Mothers" law. This law is part of the Patient Protection and Affordable Care Act and requires employers to provide reasonable break time and a private place for employees to express breast milk. The online guide, What You Need to Know About the "Break Time for Nursing Mothers" Law, answers common questions about the law and includes links to additional resources to help employers and employees understand how the law applies in their workplace.

\section{RESOURCES ON BREASTFEEDING AND RETURNING TO WORK}

\section{Breastfeeding in Childcare Toolkit}

<https://www.colorado.gov/pacific/cdphe/breastfeeding-friendly-child-care-professionals $>$

This toolkit was developed by the Colorado Department of Public Health \&

Environment. The purpose of the toolkit is to provide child care professionals with information 
and best practices to support the health and breastfeeding goals of mothers and babies. Resources for both child care centers and home child care include an overview of the benefits of breastfeeding, a breastfeeding-friendly assessment, an action plan, sample policies, tips for communicating with parents, guidelines for milk storage, instructions for paced bottle feeding, and other topics related to the care of the baby. There is also information for parents on breastfeeding education and tips for starting a breastfed baby in childcare.

\section{WomensHealth.gov: Supporting Nursing Moms at Work \\ $<$ https://www.womenshealth.gov/supporting-nursing-moms-work/>}

This resource from the Office on Women's Health offers creative and cost-effective solutions to support parents' breastfeeding goals in any industry setting. Employers and employees can search by industry or type of solution to find options to fit their workplace setting. The site gives examples of how to provide employees with time and space to pump milk or breastfeed during the workday, and highlights businesses that have been successful in implementing these solutions. There is also a link to the toolkit, The Business Case for Breastfeeding, which educates employers on the benefits of supporting the breastfeeding goals of their employees.

\section{RESOURCES FOR BREASTFEEDING SUPPORT \& ADVOCACY}

\section{Find a Lactation Consultant}

$<\underline{\text { http://www.ilca.org/why-ibclc/falc }>}$ 
The International Lactation Consultant Association maintains a directory of International Board Certified Lactation Consultants (IBCLC) who are members of their organization. An IBCLC specializes in the clinical management of breastfeeding. It is recommended that parents meet with a lactation consultant before birth to plan for breastfeeding. After birth, a lactation consultant can help parents get started with breastfeeding, answer breastfeeding questions, and help troubleshoot challenges that the mother or baby may experience. If parents cannot find a local IBCLC through this directory, they can find help through other organizations listed below.

\section{Finding a Breastfeeding-Friendly Doctor}

<https://www.healthychildren.org/English/ages-stages/prenatal/decisions-tomake/Pages/Finding-a-Breastfeeding-Friendly-Doctor.aspx $>$

Not all doctors are supportive of breastfeeding or have adequate knowledge to encourage the breastfeeding goals of their patients. The American Academy of Pediatrics encourages parents to ask potential pediatricians about their ability to support breastfeeding families. This article provides a list of eight questions that assess breastfeeding knowledge and experience, and the doctor's connection to lactation consultants and other support resources.

\section{La Leche League}

$<$ https://www.llli.org/>

The La Leche League is an international organization that provides education and encouragement for breastfeeding families. Through the website, parents can engage in online forums, search for a local La Leche League Leader or support group, and read articles from 
Breastfeeding Info A-Z or the Breastfeeding Today magazine. The support groups provide peer support and are led by a mother who has prior experience with breastfeeding.

\section{U.S.D.A. Loving Support Makes Breastfeeding Work $<\underline{\text { https://lovingsupport.fns.usda.gov/> }}$}

The United States Department of Agriculture (USDA) funds the Special Supplemental Nutrition Program for Women, Infants and Children (WIC). WIC serves low-income women who are pregnant, postpartum, or breastfeeding and infants and children up to five years old. Breastfeeding aids, educational materials, and peer counseling are offered as a part of WIC services. The Loving Support Makes Breastfeeding Work website provides training materials for WIC staff, and education and advocacy handouts for breastfeeding mothers and their families (Figure 3). The handouts provide information on the benefits of breastfeeding and offer tips for fathers and grandparents in helping with breastfeeding.

\section{[PLACE FIGURE 3 HERE]}

\section{Text for FIGURE 3: Figure 3. U.S.D.A. Loving Support Makes Breastfeeding Work website}

\section{CONCLUSION}

Finding evidence-based information on breastfeeding and connecting with community resources can be challenging for parents. Breastfeeding is a learned skill and it is important for parents to have access to the education and coaching needed to be successful. As organizations and health professionals work towards increasing the rates for continued breastfeeding past six 
months, it is important that the larger community exhibits practices and policies that are supportive of the breastfeeding relationship. This article provides a sample of some of the most trusted online breastfeeding resources available for information, education, and advocacy.

\section{REFERENCES}

American Academy of Pediatrics. 2012. Breastfeeding and the Use of Human Milk. Pediatrics. 129(3):e827. Accessed January 14, 2019. doi:10.1542/peds.2011-355

Antsey, EH. J Chen, LD Elam-Evans, and CG Perrine. 2017. Racial and Geographic Differences in Breastfeeding — United States, 2011-2015. Morbidity and Mortality Weekly Report. 66(27):723-727. Accessed January 15, 2018. http://dx.doi.org/10.15585/mmwr.mm6627a3

Centers for Disease Control and Prevention. 2018. Breastfeeding Report Card: United States, 2018. Atlanta, GA: Centers for

Disease Control and Prevention. Accessed January 15, 2019. https://www.cdc.gov/breastfeeding/pdf/2018breastfeedingreportcard.pdf

Jones, KM. ML Power, JT Queenan, and J Schulkin. 2015. Racial and Ethnic Disparities in Breastfeeding. Breastfeeding Medicine. 10(4):186-196. Accessed January 14, 2019. https://doi.org/10.1089/bfm.2014.0152

Kim, JH, and EB Froh. 2012. What Nurses Need to Know Regarding Nutritional and Immunobiological Properties of Human Milk. Journal of Obstetric, Gynecologic, and Neonatal Nursing, 41(1): 122-137. Accessed January 14, 2019. https://doi.org/10.1111/j.1552-6909.2011.01314.x

Lessen, R and K Kavanaugh. 2015. Position of the Academy of Nutrition and Dietetics: 
Promoting and Supporting Breastfeeding. Journal of the Academy of Nutrition and Dietetics, 115(3): 444-449. Accessed January 14, 2019. https://doi.org/10.1016/j.jand.2014.12.014

Odom, EC, R Li, KS Scanlon, CG Perrine, and L Grummer-Strawn. 2013. Reasons for Earlier Than Desired Cessation of Breastfeeding. Pediatrics. 131(3):e726-e732. Accessed January 14, 2019. doi: 10.1542/peds.2012-1295

Office of Disease Prevention and Health Promotion. 2010. Maternal, Infant, and Child Health. HealthyPeople2020. Accessed January 14, 2019. https://www.healthypeople.gov/2020/topics-objectives/topic/maternal-infant-and-childhealth

Office of the Surgeon General (US); Centers for Disease Control and Prevention (US); Office on Women's Health (US). 2011. The Surgeon General's Call to Action to Support Breastfeeding. Rockville (MD): Office of the Surgeon General (US). Accessed January 14, 2019. https://www.ncbi.nlm.nih.gov/books/NBK52682/

Sriraman, NK and A Kellams. 2016. Breastfeeding: What are the Barriers? Why Women Struggle to Achieve Their Goals. Journal of Women's Health. 25(7):714-722. Accessed January 14, 2019. doi: 10.1089/jwh.2014.5059

Witkowska-Zimny, M and E Kaminska-El-Hassan. 2017. Cells of Human Breast Milk. Cellular \& Molecular Biology Letters. 22: 11. Accessed January 14, 2019. https://doi.org/10.1186/s11658-017-0042-4

World Health Organization. 2003. Global Strategy for Infant and Young Child Feeding. Geneva, Switzerland: World Health Organization. Accessed January 14, 2019. http://apps.who.int/iris/bitstream/handle/10665/42590/9241562218.pdf 